\title{
Feminicídios: conceitos, tipos e cenários
}

\author{
Femicides: concepts, types and scenarios
}

Stela Nazareth Meneghel ${ }^{1}$

Ana Paula Portella ${ }^{2}$

\footnotetext{
${ }^{1}$ Escola de Enfermagem, Universidade Federal do Rio Grande do Sul. R. São Manoel 963, Rio Branco. Porto Alegre RS Brasil. stelameneghel@gmail.com ${ }^{2}$ Núcleo de Estudos e Pesquisas em Violência, Criminalidade e Políticas Públicas, Universidade Federal de Pernambuco. Recife PE Brasil.
}

\begin{abstract}
This text is a theoretical essay that discusses the concepts, types and scenarios of feminicides, and presents some proposals for the prevention of these premature, unjust and avoidable deaths. The text revisits the original concept of femicide proposed by Diana Russell and Jane Caputti and shows new and old scenarios where these crimes occur. It points to patriarchy, understood as being a hierarchical system of power between men and women, as one of the main determinants of these deaths. It ends by presenting actions and proposals to prevent and combat these gender crimes.
\end{abstract}

Key words Femicides, Feminicides, Violence against women
Resumo Este texto é um ensaio teórico que discute os conceitos, os tipos e os cenários de feminicídios e apresenta algumas propostas para a prevenção destas mortes prematuras, injustas e evitáveis. $O$ texto traz o conceito original de femicídio proposto por Diana Russel e Jane Caputti, caracteriza tipos e mostra cenários novos e antigos onde estes crimes ocorrem. Aponta o patriarcado, entendido como sistema hierárquico de poder entre homens e mulheres, como um dos principais determinantes destas mortes. Finaliza apresentando ações e propostas para prevenir e combater estes crimes de gênero.

Palavras-chave Femicídios, Feminicídios, Violência conta a mulher 


\section{Introdução}

Este artigo é um ensaio teórico que discute conceitos e características de crimes de gênero perpetrados contra mulheres, atualmente denominados de femicídios e/ou feminicídios. Neste texto, respeitaremos o conceito adotado pelas autoras originalmente citadas, reportando-se a femicídio ou feminicídio. O texto divide-se em quatro partes: uma introdução, que apresenta o itinerário de pesquisas das autoras no tema da violência contra a mulher; um subcapítulo que discute conceitos e tipos; uma seção que mostra os cenários antigos e atuais e, finalmente, uma síntese de algumas ações nos diferentes âmbitos da sociedade que visam a prevenção destes crimes. Salienta-se que o feminicídio é a etapa final do continuum da violência contra a mulher, muitas destas mortes são "anunciadas” e evitáveis.

Uma das autoras iniciou o estudo deste tema com a pesquisa "Femicídios e assassinatos baseados em gênero no Rio Grande do Sul”, financiada pelo CNPq através do Edital 20-2010 Relações de Gênero, Mulheres e Feminismos, um projeto que atuou na intersecção do campo da saúde coletiva e dos estudos de gênero, elegendo o femicídio como um indicador para identificar situações de iniquidade de gênero na população. Os resultados quantitativos desta pesquisa ${ }^{1,2}$ mostraram associação entre mortalidade por homicídios masculinos e mortalidade feminina por agressão, em todos os recortes territoriais trabalhados: Unidades da Federação (UF), Microrregiões homogêneas do Rio Grande do Sul (MCH-RS) e municípios com população maior de 400.000 habitantes, podendo-se afirmar que os locais mais perigosos para os homens também o são para as mulheres. Na etapa qualitativa deste projeto, em que se analisaram inquéritos policiais de assassinatos de mulheres em Porto Alegre, 64\% destas mortes foram tipificadas como feminicídios ${ }^{3}$.

A segunda autora defendeu recentemente a tese de doutoramento denominada "Como morre uma mulher? Configurações da violência letal contra mulheres em Pernambuco" cujo principal objetivo foi compreender e analisar as dinâmicas sociais que produzem este tipo de violência e o conjunto das situações em que as mulheres são assassinadas, incluindo também os homicídios de homens. A autora identificou quatro configurações de homicídios no estado de Pernambuco: criminalidade, violência doméstica e familiar, violência interpessoal e violência cometida por parceiro íntimo. Com exceção do contexto da violência interpessoal, as mulheres são vitimadas em todas as configurações. A distribuição destes crimes no território do estado não é homogênea e está associada a fatores macrossociais: desigualdade de renda e taxa de urbanização, e a fatores relacionados às desigualdades de gênero, como chefia feminina do domicílio e taxa de fecundidade total. Os resultados demonstram que os contextos dos homicídios de mulheres são diversificados e obedecem a dinâmicas sociais distintas, nas quais o marcador de gênero, mesmo de modos diferentes, está sempre atuante ${ }^{4}$.

Dados do Mapa da Violência no Brasil ${ }^{5}$ mostram taxas ascendentes de mortes femininas por agressão no período de 1980-2010 e coeficientes de mortalidade que passaram de 2,3/100.000 para $4,8 / 100.000$, representando um aumento de $111 \%$ no período. Atualmente, o Brasil ocupa o $5^{\circ}$ posto em escala mundial, ficando abaixo apenas de El Salvador, Colômbia, Guatemala e Rússia.

É provável que no crescimento das taxas observado nesse período estejam operando de modo articulado elementos da subordinação de gênero e raça e da situação socioeconômica em contextos de criminalidade urbana, o que cria uma nova condição de vítima para as mulheres. Uma parcela considerável dos feminicídios ocorridos no Brasil, nos últimos anos, relaciona- se à dinâmica do tráfico e do uso de drogas e aos homicídios sexistas ${ }^{6}$.

Este ensaio tem por objetivo refletir sobre os tipos e os cenários dos feminicídios e apontar o quanto a inter-relação entre as condições de gênero, raça e situação socioeconômica no contexto do capitalismo patriarcal está agudizando a vulnerabilidade das mulheres e requer novas compreensões e explicações teóricas.

\section{Conceitos e situações de risco}

A ocorrência dos homicídios masculinos, na maioria dos países, é superior aos femininos, porém, a menor magnitude dos assassinatos femininos não confere importância secundária a esse evento, pois a maioria destas mortes por agressão possui uma direcionalidade única sendo perpetrada por homens com os quais as mulheres se relacionam intimamente ${ }^{7}$. Nos Estados Unidos, $35 \%$ dos assassinatos de mulheres são cometidos por parceiro íntimo, enquanto que apenas 5\% dos homicídios masculinos são efetuados por mulheres, a maioria dos quais em autodefesa ${ }^{8,9}$.

$\mathrm{O}$ assassinato de mulheres é habitual no regime patriarcal, no qual elas estão submetidas ao controle dos homens, quer sejam maridos, fami- 
liares ou desconhecidos. As causas destes crimes não se devem a condições patológicas dos ofensores, mas ao desejo de posse das mulheres, em muitas situações culpabilizadas por não cumprirem os papeis de gênero designados pela cultura ${ }^{10,11}$.

As violências contra as mulheres compreendem um amplo leque de agressões de caráter físico, psicológico, sexual e patrimonial que ocorrem em um continuum que pode culminar com a morte por homicídio, fato que tem sido denominado de femicídio ou feminicídio ${ }^{12}$. No seminário internacional realizado em 2005, Feminicídio, Política e Direito, Diana Russel considerou adequada a tradução do inglês "femicide" para o espanhol "femicídio", para evitar a feminização da palavra homicídio. Porém, autores como Marcela Lagarde ${ }^{13}$ diferenciam femicídio, ou assassinato de mulheres, de feminicídio, ou assassinato de mulheres pautado em gênero em contextos de negligência do Estado em relação a estas mortes, configurando crime de lesa humanidade.

O debate acerca do uso de um ou outro termo ainda é recente e por se tratar de um conceito relativamente novo houve países que optaram por utilizar na tipificação legal o termo femicídio, enquanto outros optaram pelo uso de feminicídio, ambos para designar o assassinato misógino de mulheres ${ }^{14}$. México, Nicarágua e República Dominicana incorporaram na legislação o termo feminicídio, enquanto Honduras, Chile e Guatemala optaram pelo uso de femicídio ${ }^{15}$.

$\mathrm{O}$ assassinato intencional de mulheres cometido por homens é a manifestação mais grave da violência perpetrada contra a mulher e, em sociedades patriarcais, a condição feminina é o fator de risco mais importante para a violência letal, embora possa haver maior incidência em mulheres que possuem condicionantes raciais, étnicos, de classe social, ocupação ou geracionalidade ${ }^{16}$.

O conceito de femicídio foi utilizado pela primeira vez por Diana Russel em 1976, perante o Tribunal Internacional Sobre Crimes Contra as Mulheres, realizado em Bruxelas, para caracterizar o assassinato de mulheres pelo fato de serem mulheres ${ }^{17}$, definindo-o como uma forma de terrorismo sexual ou genocídio de mulheres. $\mathrm{O}$ conceito descreve o assassinato de mulheres por homens motivados pelo ódio, desprezo, prazer ou sentimento de propriedade. Russel ancora-se na perspectiva da desigualdade de poder entre homens e mulheres, que confere aos primeiros o senso de entitlement - a crença de que lhes é assegurado o direito de dominação nas relações com as mulheres tanto no âmbito da intimidade quanto na vida pública social - que, por sua vez, autoriza o uso da violência, inclusive a letal, para fazer valer sua vontade sobre elas. O femicídio, assim, é parte dos mecanismos de perpetuação da dominação masculina, estando profundamente enraizado na sociedade e na cultura. São expressões deste enraizamento a identificação dos homens com as motivações dos assassinos, a forma seletiva com que a imprensa cobre os crimes e com que os sistemas de justiça e segurança lidam com os casos. O fato das mulheres, muitas vezes, negarem a existência do problema é atribuído à repressão ou negação produzida pela experiência traumática do próprio terrorismo sexista, além da socialização de gênero, em que a ideologia de gênero (ideologia considerada aqui no seu aspecto negativo) é utilizada para naturalizar as diferenças entre os sexos e impor estes padrões e papeis como se fossem naturais ou constituintes da natureza humana ${ }^{18}$.

O femicídio compreende um vasto conjunto de situações e não apenas as ocorridas no ambiente doméstico ou familiar. Inclui mortes provocadas por mutilação, estupro, espancamento, as perseguições e morte das bruxas na Europa, as imolações de noivas e viúvas na Índia e os crimes de honra em alguns países da América Latina e do Oriente Médio. A morte das mulheres representa então a etapa final de um continuum de terror que inclui estupro, tortura, mutilação, escravidão sexual (particularmente na prostituição), incesto e abuso sexual fora da família, violência física e emocional, assédio sexual, mutilação genital, cirurgias ginecológicas desnecessárias, heterossexualidade compulsória, esterilização e/ou maternidade forçada, cirurgias psíquicas, experimentação abusiva de medicamentos, negação de proteínas às mulheres em algumas culturas, cirurgias cosméticas e outras mutilações em nome do embelezamento. Para as autoras sempre que essas formas de terrorismo resultarem em morte tem-se um femicídio ${ }^{18}$. Descrito desta forma, o femicídio seria parte de mecanismos socioculturais amplos, que ultrapassam em muito o âmbito estrito das relações entre homens e mulheres. Muitas das práticas elencadas - como a mutilação genital e os procedimentos médicos - são realizadas por mulheres e, na maior parte das vezes, resultam de disposições institucionais e não individuais ou pessoais. Tamanha abrangência termina por conferir à sociedade patriarcal uma natureza terrorista, que produziria todas as situações de abuso e violência sofridas pelas mulheres, sendo o femicídio o desfecho fatal destas situações.

Apesar deste espectro tão amplo de situações, que apontam em grande medida para contextos 
de abuso institucional, a tendência de associar o femicídio à violência cometida por parceiro íntimo permanece forte na análise de Russel e Caputti e segue no imaginário coletivo e mesmo nas produções científicas da atualidade. Desta maneira o femicídio cometido por um familiar, amigo ou conhecido do sexo masculino, ou a situação do casal heterossexual, é a que apresenta o maior risco de morte para as mulheres.

Em países como EUA, Canadá e Costa Rica, $60 \%$ a $70 \%$ dos homicídios de mulheres correspondem a femicídios ${ }^{16,19}$. A dominação patriarcal explica a desigualdade de poder que inferioriza e subordina as mulheres aos homens, estimulando o sentimento de posse e controle dos corpos femininos e o uso da violência como punição e mecanismo para mantê-las na situação de subordinação. Assim, os feminicídios são mortes femininas que se dão sob a ordem patriarcal, uma forma de violência sexista que não se refere a fatos isolados, atribuídos a patologias ou ciúmes, mas expressa ódio misógino, desprezo às mulheres $\mathrm{e}$ constituem mortes evitáveis e, em grande maioria, anunciadas, já que grande parte representa o final de situações crescentes de violências ${ }^{20}$.

Há uma relação entre a violência estrutural de uma sociedade e o tipo de feminicídio mais frequente. Os perpetrados por parceiro íntimo atingem maiores proporções quando a taxa total de homicídios é pequena, ou seja, quando a violência estrutural tem baixa prevalência. Em locais com altas taxas de mortalidade masculina por agressão predominam os crimes cometidos por desconhecidos e, em contextos de criminalidade, onde a violência estrutural é maior, as mulheres são assassinadas na esfera pública por gangues e grupos armados, havendo uma alta prevalência de mortes perpetradas por desconhecidos, com violações sexuais e execuções ${ }^{21}$.

$\mathrm{O}$ aumento da violência letal entre homens pode ocasionar crescimento dos homicídios entre mulheres, uma vez que sociedades violentas para com os homens possuem configurações socioculturais que produzem também altas taxas de violência contra mulheres, como o machismo, o culto à virilidade e o padrão de resolução de conflitos violento e privado ${ }^{1,22}$. Estudos que investigaram a associação entre estrutura social e homicídios evidenciaram que onde a desorganização social, a privação socioeconômica, a instabilidade social e a criminalidade são maiores há mais homicídios de ambos os sexos ${ }^{23-25}$.

Mulheres assassinadas encontram-se predominantemente entre adolescentes e adultas jovens. $\mathrm{O}$ assassinato representa uma das primeiras causas de morte em mulheres jovens e adolescentes nos Estados Unidos 9 . Em grande parte dos países, as vítimas são jovens, não brancas, pobres e vivem em espaços urbanos onde a segurança é mínima ou inexistente. A maioria destas mortes não é investigada pelas instituições policiais, havendo arquivamento de grande parte dos processos. Estes dados reforçam a ideia de que o feminicídio é um tipo de crime de poder e dominação, atingindo os grupos mais fragilizados na sociedade $^{26}$ e que é mais frequente nos locais onde o Estado é tolerante com a violência, havendo impunidade para com os agressores ${ }^{27}$. Portanto, os homicídios - tanto de homens quanto de mulheres - concentram-se em áreas onde são precárias as condições sociais de existência coletiva e onde a qualidade de vida é degradada. O diferencial de risco para as negras e as pobres evidencia que há para os homens, mas também para as mulheres, a "distribuição desigual do direito à vida"28.

Em relação à vitimização feminina, Russel e Caputti ${ }^{18}$ partiram do pressuposto de que, em uma sociedade racista e sexista, os fatores individuais teriam menor influência do que os fatores socioculturais, uma vez que tanto as pessoas que apresentam distúrbios psicológicos quanto aquelas consideradas "normais", frequentemente tomam atitudes racistas e sexistas legitimadas socialmente. A violência contra as mulheres, nessa perspectiva, teria como objetivo a preservação da supremacia masculina no âmbito das relações interpessoais e no nível macrossocial. O estupro, por exemplo, seria uma expressão direta do que ela denomina política sexual, uma afirmação das normas machistas e uma forma de terrorismo que preserva o status quo, enquanto o assassinato de mulheres seria tão somente a forma mais extrema de terrorismo sexista. Essa interpretação representa uma nova compreensão política do problema da violência contra as mulheres e, por isso, foi preciso construir um novo conceito, capaz de refletir a nova abordagem, esse conceito é o femicídio.

\section{Cenários}

Os cenários onde ocorrem os feminicídios ajudam a compreender os seus determinantes, alguns conhecidos de longa data, outros emergentes na atualidade. Os mais conhecidos e estudados são os cenários familiares e domésticos, já que a família em sociedades patriarcais confere todo o poder ao homem, e nas relações entre parceiros íntimos as mulheres são consideradas propriedade dos maridos, companheiros, namorados e ex-companheiros ${ }^{29}$. 
Fatores que podem aumentar a vulnerabilidade das mulheres de serem mortas pelos parceiros íntimos incluem a disparidade de idade entre os cônjuges, a situação marital não formalizada, as tentativas prévias da mulher em obter a separação (especialmente nos três meses que antecederam o assassinato) e histórias repetidas de violência e agressões. Grande parte dos homens que assassinam as esposas não difere de seus pares na sociedade e são considerados "comuns e convencionais", o que é ainda mais perigoso ${ }^{30,31}$ porque há uma tendência de atribuir o delito a uma explosão de cólera, ou um motivo "passional” impossível de ser previsto e prevenido. Por esse motivo, considerar o femicídio como uma explosão passional ou atribui-lo à doença do agressor, significa retirar a conotação social e de gênero do crime, reduzindo-o à esfera individual.

Em mais de 70\% dos assassinatos de mulheres por parceiro íntimo há relatos de violência de gênero em níveis ascendentes em termos de frequência e gravidade ${ }^{32}$. Mulheres que possuem melhores níveis de escolaridade, situação socioeconômica e laboral que os companheiros estão em maior risco ${ }^{8,33}$, indicando a presença do fenômeno chamado backlash ou feminicidios perpetrados por homens (companheiros ou conhecidos) quando estão em situação socioeconômica ou social desvantajosa em relação às mulheres ou quando elas querem separar-se e eles não o desejam. Dentre os agressores há uma sobreprevalência de homens desempregados, que possuem armas de fogo, histórico de agressões e ameaças de morte dirigidas à vítima ${ }^{8}$.

Outra situação que pode levar ao feminicídio é a agressão sexual, que ocorre em todas as classes sociais, no âmbito público e no privado. A violência sexual representa situação em que as mulheres estão na posição de meros objetos descartáveis, tornando esse ato extremamente perigoso pela necessidade do agressor de eliminar testemunhas e vestígios, matando a vítima após uma violação sexual ${ }^{29}$.

Um terceiro cenário corresponde à exploração e tráfico sexual de mulheres e meninas, que constituem um dos negócios mais lucrativos a nível mundial, contando com a proteção de políticos, policiais e membros do sistema judiciário de muitos países. Nas redes de tráfico sexual, as mulheres são um objeto valioso, mas podem ser descartadas facilmente, quando adoecem, ameaçam fugir ou não estão cumprindo as tarefas impostas nas situações de trabalho a que são submetidas. No comércio sexual, em que predomina a "coisificação" feminina, a vida pouco vale. Isso implica em alta prevalência de mortes de mulheres pelos clientes, cafetões ou chefes do tráfico. Além do mais, os estereótipos veiculados pela ideologia patriarcal, produzem uma situação de indiferença em relação a essas mortes, geralmente havendo atribuição de culpa às vítimas. $\mathrm{O}$ ódio misógino é tão elevado em relação às trabalhadoras do sexo, a ponto de tonarem-se alvo de ações internacionais diretas de extermínio sob o rótulo de limpeza social ${ }^{29}$. Mulheres que exercem a prostituição possuem um risco em torno de 50 vezes maior que a população feminina geral ${ }^{34}$, já que o cliente ao pagar pelo sexo, sente-se no direito de dispor do corpo da mulher.

Atividades ilegais referentes ao tráfico de drogas, armas e migração clandestina têm contado com participação cada vez maior de mulheres. Nesse contexto, elas muito facilmente se convertem em território de vingança e, pela maior facilidade de serem localizadas, são executadas em lugar dos companheiros, fazendo com que esse tipo de crime também se caracterize como femicídio, embora não seja visto como tal pelos operadores policiais e população ${ }^{29}$.

A presença destes contextos e condicionantes pode coexistir havendo várias situações superpostas, dificultando a identificação e o enfrentamento das causas. Enfim, existe um cenário de misoginia e crueldade em que as mortes são acompanhadas de violações e os corpos são mutilados, desnudados e desqualificados. O feminicídio representa então uma mensagem enviada às mulheres (para aterrorizá-las e mantê-las submissas) e aos outros homens (para demarcar território e mostrar quem é que manda) $)^{35,36}$.

Novas tipologias e cenários incluem as mortes por conexão: quando uma mulher está na linha de fogo em que um homem mata ou tenta matar outra mulher; feminicídios sexuais sistêmicos, precedidos de sequestro, tortura e estupro; morte de mulheres que exercem prostituição ou ocupações estigmatizadas; morte de mulheres em situação de tráfico ou contrabando de pessoas e finalmente os feminicídios em que há marcas de racismo, quando há ódio à origem étnica, racial ou traços fenotípicos da mulher e quando há preconceitos em relação à orientação sexual, incluindo feminicídios transfóbicos e lesbofóbicos.

Além dessas, também se consideram feminicídios as execuções de mulheres em conflitos armados, a perseguição e morte de militantes políticas e sociais, a eliminação de grupos considerados inferiores em ações de "limpeza racial" como o que acontece com mulheres pertencentes a minorias étnicas. 
Ao caracterizar esse tipo de mortes não se pode deixar de analisar as novas configurações na organização social do trabalho, a crescente urbanização da população e os movimentos migratórios, os reflexos globais de mudanças de comportamento incidindo em culturas de honra, a proliferação de máfias e organizações criminosas que têm explorado as mulheres e as descartado quando não são mais necessárias ou para intimidar as instituições sociais e as outras mulheres. A coexistência de fenômenos tradicionais e modernos tem levado à vulnerabilização cada vez maior dos grupos mais frágeis e sem redes de proteção, incluindo as mulheres jovens, pobres e migrantes, vítimas preferenciais deste tipo de crime.

\section{Enfrentamentos}

Para fazer frente aos femicídios, diz Dora Munevar ${ }^{37}$ é preciso realizar as ações de nomear, visibilizar e conceituar as mortes violentas de mulheres, o que constitui o exercício material do direito a ter direitos. Do mesmo modo, há necessidade de definir os elementos objetivos e subjetivos do tipo penal que sancione esses crimes.

Para o monitoramento dos feminicídios em um território é preciso dispor de informações fidedignas. No Brasil, as declarações de óbito que fazem parte do Sistema de Informação de Mortalidade/DATASUS não contêm dados referentes à causa do crime, sendo impossível classificar as mortes femininas por agressão, como femicídios ou feminicídios, já que não contam com informação referente ao agressor e à intencionalidade do evento. Outros documentos que se referem aos óbitos femininos por agressão, mas não os tipificam são os prontuários de serviços de emergência, laudos periciais e inquéritos periciais, porém o acesso é restrito, o manuseio é difícil e podem demandar um longo espaço de tempo até sua conclusão.

Em 2006, o Ministério da Saúde implantou o sistema de Vigilância de Violências e Acidentes (VIVA) no âmbito do Sistema Único de Saúde (SUS), em dois componentes: (1) vigilância de violência doméstica, sexual, e/ou outras violências interpessoais e autoprovocadas (VIVA-Contínuo), e (2) vigilância de violências e acidentes em emergências hospitalares (VIVA-Sentinela) ${ }^{38}$. Mesmo após a criação deste sistema, as violências têm sido pouco notificadas, principalmente aquelas contra a mulher. No Brasil, assim como em outros países, ainda não há bases de dados fidedignas que indiquem a prevalência da violência contra a mulher e identifiquem as que estão em maior risco de morte, para que possam ser tomadas medidas de proteção ${ }^{14}$.

Estudos sobre as rotas críticas percorridas pelas mulheres no enfrentamento das violências mostram que o sistema jurídico-policial é o mais procurado e o setor saúde não tem funcionado como porta de entrada para o diagnóstico e o acolhimento de casos ${ }^{32}$. Profissionais do setor saúde dificilmente consideram a violência contra a mulher como um problema de saúde pública, embora tenha sido definida como tal pela Organização Mundial da Saúde nos anos 1990. Dentre os motivos para esta omissão pode-se elencar a não inclusão deste tema nos cursos da área da saúde, além da percepção conservadora e tradicional sobre os papeis de gênero por parte dos operadores que acreditam que a violência doméstica pertença à esfera do privado e que as mulheres instigam os homens à violência ou não sabem se proteger. Essas percepções fazem com que, em muitas situações, a violência fique invisibilizada nos serviços que não percebem nem mesmo o risco de morte destas usuárias ${ }^{39,40}$.

Outro fator que obstaculiza a atuação dos trabalhadores da saúde é a insuficiência ou inexistência de equipamentos sociais como serviços especializados e casas de passagem que possam albergar e proteger essas mulheres. $\mathrm{O}$ fato de realizar um diagnóstico de violência de gênero perpetrada contra uma mulher e não ter recursos humanos e materiais para oferecer é uma situação que gera mal-estar, ansiedade e angústia, fazendo com que muitos trabalhadores prefiram ignorar este problema.

Também têm sido relatados, principalmente por profissionais que atuam em regiões com a presença do tráfico, sentimentos de medo e impotência gerados pelo confronto com o crime organizado. Para o profissional da atenção básica, que está na ponta do sistema e se sente muitas vezes sozinho e sem apoio da retaguarda, efetuar um notificação de violência (que pode ser lida como denúncia; que é anônima, mas muitas vezes que todos sabem quem a produziu) pode significar exposição à retaliação por parte dos agressores. Acrescente-se a dificuldade do Estado brasileiro em proteger as testemunhas e/ou os depoentes e o rompimento do sigilo que ocorre em muitas situações pelos trabalhadores que alimentam sistemas de informação ou pelos rituais jurídicos que colocam frente a frente vítimas, réus e testemunhas.

Além do mais, os profissionais da saúde formados para oferecer ações técnicas frente às doenças sentem-se despreparados para lidar com 
um agravo cuja resolução implica em outras habilidades e atitudes. Uma abordagem equivocada é a de tratar a violência como uma doença, medicalizando e psiquiatrizando um problema cujas raízes são sociais ${ }^{41}$.

A violência contra a mulher é um evento de caráter crônico, portanto a resolução demanda tempo e as vítimas precisam ser atendidas, acompanhadas e fortalecidas em linhas de cuidado que podem demandar longos períodos de tempo. Por outro lado, o feminicídio é uma ação que pode ocorrer abruptamente após uma ameaça ou conflito e, neste caso, as providências de proteção da mulher precisam ser oportunas e rápidas.

Há necessidade de implantar protocolos nos serviços de saúde, tanto na atenção básica, quanto nos níveis de maior complexidade, para identificar a violência contra a mulher e o risco de morte. Deve-se perguntar sempre se a mulher sofreu/sofre violência, para romper os tabus de que “disso não se fala”. É preciso ouvir sem julgar, não pressionar a mulher para denunciar, traçar planos de cuidado, ajudar a construção de redes de suporte e, principalmente, identificar quando a situação é de risco imediato e, nestes casos, agir rapidamente para proteger a vítima. Em suma, elaborar um plano terapêutico singular para cada mulher afetada pela violência ${ }^{42}$.

De acordo com a normativa internacional, os Estados nos casos de violência contra as mulheres por razões de gênero, possuem quatro obrigações: atuar com diligência, prevenção, investigar e sancionar, e garantir uma justa e eficaz reparação ${ }^{20}$.

A formulação da Lei Maria da Penha (Lei no 11.340), em 2006, constituiu um dos marcos legais para o enfrentamento dos crimes de gênero. Com a lei Maria da Penha, a violência deixou de ser considerada como crime de menor potencial ofensivo, foi conceituada e tipificada, sendo rapidamente conhecida e incorporada no discurso das mulheres do país, independentemente de posição social ${ }^{41}$.

Uma década depois, frente ao recrudescimento de assassinatos contra a mulher e à positivação em lei efetuada por vários países, inicia no país a discussão sobre uma lei específica para o feminicídio. O Brasil regulamentou esta lei, após uma série de debates e discussões com vários setores da sociedade, instituições e movimentos sociais. O crime de feminicídio foi sancionado através da Lei, que passa a considerar a questão de gênero como circunstância qualificadora do homicídio. $\mathrm{O}$ assassinato de uma mulher cometido por razões de gênero, quando o crime envolve violência doméstica e familiar e/ou menosprezo ou discriminação à condição de mulher passa a ser considerado feminicídio.

Em 2016, é publicado o documento "Diretrizes Nacionais para investigar, processar e julgar com perspectiva de gênero as mortes violentas de mulheres", uma adaptação do Modelo de Protocolo latino-americano para investigação das mortes violentas de mulheres por razões de gênero. As Diretrizes visam colaborar para o aprimoramento da investigação policial, do processo judicial e do julgamento das mortes violentas de mulheres de modo a evidenciar as razões de gênero na ocorrência dessas mortes. Adotar esta perspectiva é fundamental para que o Estado consiga agir de modo mais eficiente para prevenir e punir os feminicídios ${ }^{20}$.

Embora pontuais, há experiências, projetos e programas bem sucedidos, principalmente quando existem redes, parcerias com os movimentos sociais e protagonismo das mulheres. Um exemplo deste tipo de intervenção foi a Patrulha Maria da Penha, organizada no ano de 2012 no estado do Rio Grande do Sul para atender regiões de elevada vulnerabilidade social. A patrulha constituiu uma ação intersetorial criada pelas secretarias da Segurança Pública e de Políticas paras as Mulheres, operacionalizada pela Brigada Militar e Polícia Civil, fiscalizando o cumprimento da medida protetiva de urgência solicitada por mulheres vítimas de violência doméstica ${ }^{43}$.

A patrulha teve ampla aceitação pela população e pelos setores policial e jurídico devido ao impacto positivo que alcançou, evitando reincidências e efetuando a prisão de agressores que descumpriam as medidas protetivas. Porém, a mudança de governo e as restrições que seguiram, como a extinção da Secretaria de Políticas para Mulheres, tanto no âmbito do estado quando do país, indicam que o projeto permanecerá apenas "no papel".

Isso significa que, a despeito da adoção de mecanismos e políticas para a erradicação da violência contra as mulheres, os Estados ainda não foram capazes de cumprir adequadamente as obrigações no tocante à prevenção, investigação, julgamento e punição dos assassinatos de mulheres. Entre os maiores desafios estão a ausência de vontade política para confrontar os crimes; os obstáculos existentes para as investigações incluindo omissões, erros e negligências; a falta de evidências para julgamento dos acusados; a revitimização da vítima; a ausência de acesso à Justiça e de assistência aos membros da família na busca do julgamento dos perpetradores de 
modo a eliminar a impunidade característica da violência contra as mulheres ${ }^{44}$.

Poderia se acrescentar ainda o caráter patriarcal da sociedade, que mantém as desigualdades de poder entre homens e mulheres e segue considerando estas como propriedade dos primeiros, que têm licença, portanto, para matá-las.

Finalmente, na medida em que todas e todos somos afetados pelas violências, é preciso que os trabalhadores sociais e de saúde, assim como os operadores do setor jurídico-policial não apenas recebam formação teórica, mas educação continuada que inclua a discussão dos casos na sua integralidade, o partilhar de experiências mesmo as mais dolorosas, o apoio e a retaguarda para a equipe e, principalmente, a capacidade de manter viva a capacidade de se indignar, sentimento que ajuda a elaborar o mal estar que nos atinge ao nos defrontarmos com o sofrimento humano e com estas mortes prematuras, evitáveis, cruéis e iníquas.

\section{Colaboradores}

SN Meneghel e AP Portella partilharam igualmente todo o processo de elaboração do artigo. 


\section{Referências}

1. Meneghel SN, Hirakata VN. Femicidios: assassinatos de mulheres no Brasil. Rev Saude Publica 2011; 45(3):56474 .

2. Leites GT, Meneghel SN, Hirakata VN. Homicídios femininos no Rio Grande do Sul, Brasil. Rev. bras. epidemiol 2014; 17(3):642-653.

3. Meneghel SN, Ceccon RF, Hesler LZ, Margarites AF, Rosa S, Vasconcelos VD. Femicídios: narrativas de crimes de gênero. Interface (Botucatu) 2013; 17(43):523533.

4. Portella AP. Como morre uma mulher? Configurações da violência letal contra mulheres em Pernambuco [tese]. Recife: Universidade Federal de Pernambuco; 2014.

5. Wailselfisz JJ. O mapa da violência 2015. Homicídios de mulheres no Brasil. Rio de Janeiro: CEBELA, FLACSO; 2015.

6. Portella AP. Violência contra as mulheres: questões e desafios para as políticas públicas. In: Carvalho FL, organizador. Observatório da Cidadania 2009. Edição Especial Diálogos sobre Violência e Segurança Pública: Razões e Urgências. Rio de Janeiro: IBASE; 2009. v. 1. p. 31-40.

7. Schraiber LB, D'Oliveira AF, Couto MT. Violência e saúde: estudos científicos recentes. Rev Saude Publica 2006; 40(N. esp.):112-120.

8. World Health Organization (WHO). Understanding and addressing violence against women. Femicide. Geneva: WHO; 2012.

9. Glass N, Laughon K, Rutto C, Campbell J. Young adult intimate partner femicide. Homicide Studies 2008; 12(2):177-187.

10. Monarrez Fragoso J. Feminicidio sexual serial em Ciudad Juarez: 1993-2001. Debate Feminista 2002; 25(13):1-16.

11. Biglia B, San Martin C. Estado de wonderbra: entretejiendo narraciones feministas sobre las violencias de género. Barcelona: Vírus Editorial; 2007.

12. Krug E, Dahlberg L, Mercy J. Informe Mundial sobre violencia y salud. Washington: OPAS/OMS; 2004.

13. Lagarde M. Por la vida y la libertad de las mujeres, fin al feminicidio. 2004. [acessado $2016 \mathrm{dez} 8$ ]. Disponível em: http://www.cimacnoticias.com.mx/especiales/comision/diavlagarde.htm

14. Comitê Latino-americano e do Caribe para a Defesa dos Direitos da Mulher (CLADEM). Contribuciones al debate sobre la tipificación penal del feminicidio/femicidio. Lima: CLADEM; 2011.

15. Fernandez A. Femicidios; la ferocidad del patriarcado. Revista Nomadias 2012; 16:47-73.

16. Carcedo A, Sagot M. Femicidio en Costa Rica 19901999. Washington: Organización Panamericana de la Salud; 2000

17. Instituto Interamericano de Derechos Humanos (IIDH). Informe regional. Situación y análisis del femicidio en la región centroamericana. Consejo Centroamericano de Procuradores de Derechos Humanos, 2006. [acessado 2016 jun 1]. Disponível em: http://apps.who. int/iris/bitstream/10665/77421/1/WHO_RHR_12.38_ eng.pdf

18. Russel D, Caputti J. Femicide: the politics of women killing. New York: Twayne Publisher; 1992.
19. Carcedo A, Sagot M. Femicidio en Costa Rica: cuando la violencia contra las mujeres mata. 2001. [acessado 2016 ago 1]. Disponível em: http://www.isis.cl/temas/ vi/reflex8.htm

20. Pasinato W, coordenador. Diretrizes nacionais Feminicídio. Investigar, processar e julgar com a perspectiva de gênero. As mortes violentas de mulheres. Brasília: ONU Mulheres, Secretaria de Política para as Mulheres, Secretaria Nacional de Segurança Pública; 2016.

21. Alvazzi del Frate A. When the victim is a women. Geneva Declaration Secretariat. 2011. [acessado 2016 ago 1]. Disponível em: http://www.genervadeclaration.org/ fileadmin/docs/GBAV2/GBAV2011_CH4.pdf

22. Ratton JL, Pavão N. Mulheres, violência e percepção da violência em Pernambuco. In: Sento-Sé JT, organizador. Segurança Pública: Outros Olhares, Novas Possibilidades. Brasília: Presidência da República/Secretaria Especial de Políticas para Mulheres; 2009. p. 88-103.

23. Fry V, Wilt S. Femicide and social disorganization. Violence against women 2001; 7(3):335-351.

24. Grana SJ. Socio-structural considerations of domestic femicide. Journal of Family Violence 2001; 16(4):421435.

25. Campbell JC, Sharps PW, Laughon K, Bloom T. Intimate partner homicide - review and implications of research and policy. Trauma, Violence and Abuse 2007; 8(3):246-269.

26. Oliveira DD, Geraldes EC, Lima RB. Primavera já partiu: relato dos homicídios femininos no Brasil. Brasília: Movimento Nacional dos Direitos Humanos (MNDH); 1998.

27. Geneva Declaration of Armed Violence. Global Burden of Armed Violence 2011. When the victim is a women. p.113-144. [acessado 2016 jun 1]. Disponível em: http://www.genevadeclaration.org/fileadmin/docs/ GBAV2/GBAV2011_CH4.pdf

28. Adorno SF. Exclusão socioeconômica e violência urbana. Sociologias 2002; 4(8):84-135.

29. Carcedo A. No olvidamos ni aceptamos: Femicidio en Centroamérica 2000-2006. San José: Associación Centro Feminista de Información y Acción (CEFEMINA); 2010.

30. Dobasch RE, Dobasch RP. Not an ordinary killer - just an ordinary guy - when men murder an intimate woman partner. Violence against women 2004; 10(6):577605.

31. Dobasch RE, Dobasch RP, Cavanagh K. "Out of the blue": men who murder an intimate partner. Feminist criminology 2009; 4(3):194-225.

32. Sagot M. Ruta crítica de las mujeres afectadas por la violéncia intrafamiliar en América Latina: estudios de caso de diez países. San José: Organização Pan-Americana de Saúde (OPAS); 2000.

33. Campbell JC, Webster D, Koziof-McLain, Block C, Campbell D, Curry MA, Gary F, Glass N, McFarlane J, Sachs C, Sharps P, Ulrich Y, Wilt SA, Manganello J, Xu X, Schollenberger J, Frye V, Laughon K. Risk factors for femicide in abusive relationships: results of a multicase case control study. Am J Public Health 2003; 93(7):1089-1097. 
34. Salfati CG. Prostitute homicides: a descriptive study. J Interpers Violence 2008; 23(4):505-543.

35. Segato R. Las estructuras elementales de la violencia. Ensayos sobre género entre la antropología, el psicoanálisis y los derechos humanos. Bernal: Universidad de Quilmes; 2003.

36. Segato R. Qué es un femicidio? Notas para um debate emergente. Brasília: UNB; 2006.

37. Munevar D. Delito de femicidio. Muerte violenta de mujeres por razones de género. Revista Estudios SocioJurídicos 2012; 14(1):135-175.

38. Brasil. Ministério da Saúde (MS). Viva: vigilância de violências e acidentes, 2006 e 2007. Brasília: MS; 2009.

39. Meneghel SN, Bairros F, Mueller B, Monteiro D, Collaziol M. Rotas críticas de mulheres em situação de violência. Cad Saude Publica 2011; 27(4):743-752.

40. Schraiber LB, D’Oliveira AF. Mulheres em situação de violência: entre rotas críticas e redes intersetoriais de atenção. Rev Med (São Paulo) 2013; 92(2):134-140.

41. Meneghel SN, Mueller B, Collaziol ME, Quadros MM. Repercussões da lei Maria da Penha no enfrentamento da violência de gênero. Cien Saude Colet 2013; 18(3):691-700.

42. Schraiber LB, D'Oliveira AF. O que devem saber os profissionais de saúde para promover os direitos e a saúde das mulheres em situação de violência doméstica [cartilha]. São Paulo: USP; 2002.

43. Spaniol M, Grsossi PK. Análise da Implantação das Patrulhas Maria da Penha nos Territórios da Paz em Porto Alegre: avanços e desafios. Textos \& Contextos 2014; 13(2):398-413.

44. ISIS Internacional. O avanço dos direitos humanos e a violência contra mulheres. Femicídio/Feminicídio. [acessado 2016 jun 1]. Disponível em: http://www.isis.cl/ temas/vi/activismo/Portugues/feminicidioPORT.pdf

Artigo apresentado em 13/01/2017

Aprovado em 18/04/2017

Versão final apresentada em 20/04/2017 